\title{
Evaluation of pemetrexed in the treatment of epithelial ovarian cancer, fallopian tube cancer, and primary peritoneal cancer: a retrospective study
}

\author{
Yanmei Wu \\ Shandong University Qilu Hospital \\ Jie Jiang ( $\square$ qljiangjie@sdu.edu.cn )
}

\section{Research}

Keywords: pemetrexed, epithelial ovarian cancer, chemotherapy

Posted Date: February 27th, 2020

DOI: https://doi.org/10.21203/rs.2.24720/v1

License: (c) (i) This work is licensed under a Creative Commons Attribution 4.0 International License. Read Full License 


\section{Abstract}

Background: The aim of this study was to evaluate the efficacy and safety of pemetrexed in the treatment of epithelial ovarian cancer, fallopian tube cancer, and primary peritoneal cancer.

Results: Patients with platinum-sensitive and platinum-resistant epithelial ovarian cancer who received pemetrexed disodium chemotherapy at Qilu Hospital of Shandong University between January 2015 and December 2018 were identified. Dose delay and adjustment were permitted when serious side effects occurred. To observe the efficacy rate and follow up on its side effects, progression-free survival and overall survival after chemotherapy were monitored. A total of 96 cases were collected, and 340 cycles of chemotherapy were administered. The overall response rate (ORR) was 32.29\% (31 patients), where 16 patients $(16.67 \%)$ had a complete response, and 15 patients $(15.62 \%)$ had a partial response. There were 68 platinum-resistant patients and 28 platinum-sensitive patients. The ORRs of platinum-sensitive and platinum-resistant patients were 42.86\% (12 patients) and 27.94\% (19 patients), respectively, $p=0.16$. The median progression-free survival (PFS) was 3.52 months and 2.97 months (HR0.62, 95\% Cl, 0.37$1.02)$, respectively, and there was no significant difference $(P=0.06)$. The median overall survival $(O S)$ of the two groups was 36 months and 18 months, respectively, and the difference was statistically significant $(p=0.01)$. There was no drug-related death in all patients, and all of the side effects were mild. The most common side effects were myelosuppression, gastrointestinal reactions and hepatotoxicity.

Conclusion: Pemetrexed disodium is effective not only for platinum-sensitive but also platinum-resistant epithelial ovarian cancer. And the side effects are tolerable. Pemetrexed disodium may be a choice for epithelial ovarian cancer, fallopian tube cancer, and primary peritoneal cancer.

\section{Backgound}

Ovarian cancer is one of the three most common gynecologic cancers in women. According to statistics $^{[1]}$, the incidence of ovarian cancer in the Asian population is as high as 9.2 per 100,000 people per year, while the mortality rate is 4.4 per 100,000 people per year. With the therapeutic strategy that includes platinum-based chemotherapy following surgery, the 5-year survival rate of patients slightly increased to $57 \%$. However, the high incidence and mortality rates of ovarian cancer seriously threaten the quality of life and life of women. Ovarian cancer can be divided into epithelial cancer, malignant germ cell tumor and sex cord stromal cell tumor, most of which are epithelial cancers, which accounts for approximately $90 \%$ of these tumors. Because there is no effective screening method and the clinical symptoms of ovarian cancer are not obvious, most patients were diagnosed at an advanced stage ${ }^{[2]}$. At present, satisfactory cytoreductive surgery and adjuvant chemotherapy based on platinum and paclitaxel with or without maintence therapies based on targeted chemotherapy drugs are recognized as effective treatments for ovarian cancer. Nevertheless, a few patients still progress during the initial platinumcontaining therapy, and most ovarian cancers recur within three years. As a result, the treatment of ovarian cancer is an urgent problem that needs to be addressed. The goals of treatment are to prolong the survival period and to improve the quality of life of ovarian cancer patients. In 2019, the 
NCCNrecommended platinum-based chemotherapy for ovarian cancer patients; however, the NCCN no longer recommended this treatment for platinum-resistant ovarian cancer patients, and single-drug chemotherapy is often used based on experience for these patients. At present, many single-drug chemotherapy regimens have similar efficacy and low efficiency: the overall response rate to topotecan was $20 \%[3]$, the overall response rate to gemcitabine was $19 \%{ }^{[4]}$, and the ORR to bevacizumab was $21 \%{ }^{[5]}$.

Pemetrexed is an anti-folic acid agent that is now used as a novel multitarget antitumor drug. This drug exerts its activities by inhibiting folate-dependent enzymes involved in purine and pyrimidine synthesis, including thymine synthase, dihydrofolate reductase,glycinamide ribonucleotide formyltransferase and aminoazole-formamide-ribonucleotide formyltransferase. Pemetrexed shows great clinical activity in many solid tumors, such as non-small cell lung cancer, breast cancer, mesothelioma, colorectal cancer, pancreatic cancer, gastric cancer, bladder cancer, cervical cancer and head and neck cancer ${ }^{[6]}$. Bone marrow suppression is the dose-limiting toxicity of this drug. Preclinical studies have claimed that adding folic acid can reduce the toxicity of pemetrexed while maintaining its antitumor activity ${ }^{[7]}$. Pemetrexed combined with cisplatin was first approved by the Food and Drug Administration (FDA) for the treatment of pleural mesothelioma in 2004 and was approved for the treatment of nonsquamous non-small cell lung cancer (NSCLC) in $2008^{[8]}$.

In relevant research of ovarian cancer treatment, pemetrexed disodium was effective for platinumsensitive and platinum-resistant ovarian cancer with tolerate toxicity ${ }^{[9]}$. Some researchers have calculated that the overall response rate to pemetrexed disodium in platinum-sensitive recurrent ovarian cancer was $32.8 \%[10]$, the overall response rate to pemetrexed disodium was $9.3 \%$ at a dose of $500 \mathrm{mg} / \mathrm{m}^{2}$, and the response rate was $10.4 \%$ at a dose of $900 \mathrm{mg} / \mathrm{m}^{2}$ in platinum-resistant recurrent ovarian cancer ${ }^{[11]}$. Therefore, the NCCN guidelines in 2014 recommended pemetrexed as an alternative treatment for recurrent ovarian cancer, and the NCCN guidelines in 2019 recommended this drug for a platinumsensitive and platinum-resistant recurrent ovarian cancer. Based on the efficacy of pemetrexed in ovarian cancer, this paper performed statistical analysis on the application, clinical response rate and related toxicity of pemetrexed in ovarian cancer patients undergoing chemotherapy at our hospital.

\section{Patients And Methods}

From January 2015 to December 2018, 96 cases of platinum sensitive (relapse 6 months after first-line platinum-containing chemotherapy) and platinum resistant (progression during first-line platinum chemotherapy or relapse within 6 months after first-line platinum chemotherapy) epithelial ovarian cancer (including epithelial fallopian tube cancer and primary peritoneal cancer) patients were identified at Qilu Hospital of Shandong University. The median age of these 96 patients was 54 years old (range: 31-77 years old). All of these patients were confirmed to have epithelial ovarian cancer (or epithelial carcinoma of the fallopian tube and primary peritoneal cancer), and most of the patients had advanced disease (97.92\% of the patients had stage III and stage IV disease). After cytoreductive surgery, chemotherapy based on platinum combined with paclitaxel was used. Most patients achieved complete 
remission and then relapsed after several months; there were also a few patients with disease progression during first-line chemotherapy. The case characteristics are shown in Table 1.

Each patient received pemetrexed (500 mg/m², D1, q3w, ivdrip.) with or without other chemotherapeutic regimens. During chemotherapy, folic acid $(400-800 \mathrm{mg} / \mathrm{d})$ was given as a supplement, and dexamethasone was given as a pretreatment before chemotherapy. Blood tests and liver and kidney function changes were monitored every week after chemotherapy. If granulocytopenia occurred, the patients were treated with recombinant human granulocyte colony-stimulating factor(G-CSF). Daily subcutaneous injection of G-CSF at does of $100 \mu \mathrm{g}$ was given until leukocyte elevate to $3.0 \times 10^{\wedge 9} / \mathrm{I}$ and neutrophil elevate to $1.5 \times 10^{\wedge} / \mathrm{I}$. Patients with anemia received iron support, and patients with thrombocytopenia were treated with recombinant human thrombopoietin. Daily subcutaneous injection of recombinant human thrombopoietin at does of $15,000 \mathrm{U}$ was given until platelet elevate to $100 \times 10^{\wedge} \mathrm{g} / \mathrm{I}$. Liver and kidney support were given when liver and kidney function damage occurred. When the neutrophil count was greater than $1.5 \times 10^{\wedge} 9 / \mathrm{I}$, the platelet count was greater than $100 \times 10^{\wedge} 9 / \mathrm{I}$, the transaminase increasion was less than 1.5 times above normal, and the blood creatinine level was less than $2 \mathrm{mg} / \mathrm{ml}$, the next cycle of chemotherapy was started.

Ultrasound examinations and serum carbohydrate antigen-125 (CA125) concentration examinations were performed to evaluate the efficacy after each course of chemotherapy (as measured by the RECIST [version 1.0] or GCIG CA-125 response criteria). Toxicity was graded based on the National Cancer Institute's Common Terminology Criteria for Adverse Events (CTC-AE) version 4.0. Data are summarized using standard descriptive statistics, and progression-free survival (PFS) and overall survival (OS) were analyzed by the Kaplan-Meier (log-rank) method.

Table 1 Patient characteristics 


\begin{tabular}{lc} 
Characteristics & $\mathrm{N}=96(100 \%)$ \\
\hline Age & $54($ range $31-77)$ \\
\hline$\square 60$ & $74(77.08 \%)$ \\
\hline$\geq 60$ & $22(22.92 \%)$
\end{tabular}

\section{Tumor histology}

\begin{tabular}{cc}
\hline Serous & $89(92.71 \%)$ \\
\hline Mucinous & $4(4.17 \%)$ \\
\hline Clear cell & $3(3.12 \%)$ \\
\hline Endometrioid & $1(0.8 \%)$ \\
\hline Unknown & $6(4.7 \%)$
\end{tabular}

\begin{tabular}{rc}
\hline Stage & \\
\hline I & $1(1.04 \%)$ \\
\hline II & $1(1.04 \%)$ \\
\hline III & $93(96.88 \%)$ \\
IV & $1(1.04 \%)$
\end{tabular}

\section{Results}

Sixty-eight patients (70.83\%) were platinum resistant among the 96 patients, 14 patients $(14.58 \%)$ developed disease progression during first-line chemotherapy with platinum, 54 patients $(56.25 \%)$ were platinum-resistant recurrent patients, and 28 (29.17\%) patients were platinum-sensitive recurrent patients. A total of 340 cycles of chemotherapy were completed, with a median chemotherapy cycle number of 3 ; this included 294 cycles (86.47\%) of pemetrexed combined with platinum chemotherapy, 13 cycles (3.82\%) of pemetrexed combined with nonplatinum chemotherapy, and 33 cycles $(9.71 \%)$ of pemetrexed alone (Table 2).

Table 2 Chemotherapy with pemetrexed disodium 


\begin{tabular}{|c|c|}
\hline Characteristics & $\mathrm{N}=96(100 \%)$ \\
\hline Chemotherapy cycles & 340』range1 9ם \\
\hline median (circles) & 3 \\
\hline 1 2circles & $30 \square 31.25 \% \square$ \\
\hline $3 \sim 4$ circles & $43 \square 44.79 \% \square$ \\
\hline 5-6 circles & $18 \square 18.75 \% \square$ \\
\hline$\geq 6$ circles & $5 \square 5.21 \% \square$ \\
\hline Chemotherapy regimens & $\mathrm{N}=340 \square 100 \%$ \\
\hline Pemetrexed + Lobaplatin & $127 \square 37.35 \% \square$ \\
\hline Pemetrexed + Nedaplatin & $57 \square 16.76 \% \square$ \\
\hline Pemetrexed + Cisplatin & $44 \square 12.94 \% \square$ \\
\hline Pemetrexed + oxaliplatin & 33ロ9.71\%ロ \\
\hline Pemetrexed + carboplatin & 33ロ9.71\%ם \\
\hline Pemetrexed +Liposome paclitaxel & $10 \square 2.94 \% \square$ \\
\hline Pemetrexed + Bevacizumab & $3 \square 0.88 \% \square$ \\
\hline Pemetrexed & $33 \square 9.71 \% \square$ \\
\hline
\end{tabular}

Among the 96 patients, the ORR was $32.29 \%$; 16 patients $(16.67 \%$ ) had a complete response (CR) to chemotherapy, whereas 15 patients (15.62\%) showed a partial response (PR). Twenty-nine patients (30.21\%) had stable disease (SD), and the overall clinical response rate was $62.5 \%$. The other $37.5 \%$ (36 patients) of patients showed progressive disease (PD). There were 28 platinum-sensitive patients and 68 platinum-resistant patients, and the ORRs were $42.86 \%$ (12 patients) and 27.94\% (19 patients), respectively; the difference was not statistically significant $(P=0.16)$ ( Table 3 ). The median progressionfree survival (PFS) of patients with platinum-sensitive ovarian cancer was 3.52 months and that of patients with platinum-resistant ovarian cancer was 2.97 months ( $\mathrm{hr} 0.62,95 \% \mathrm{Cl}, 0.37-1.02)$; there was no significant difference $(p=0.06)$. The median survival time of platinum-sensitive patients and platinumresistant patients was 36 months and 18 months, respectively; the difference was statistically significant $(p=0.01$; Figure 1 and Figure 2). 
Table 3 Response rate

\begin{tabular}{|c|c|c|c|}
\hline Response & $\begin{array}{l}\text { Platinum sensitivity } \\
\text { (No./percentage) }\end{array}$ & $\begin{array}{l}\text { Platinum resistance } \\
\text { (No./percentage) }\end{array}$ & Total \\
\hline $\begin{array}{l}\text { Complete } \\
\text { response(CR) }\end{array}$ & $9(32.14 \%)$ & $7(10.29 \%)$ & $16(16.67 \%)$ \\
\hline $\begin{array}{l}\text { Partial Response } \\
\text { (PR) }\end{array}$ & $3(10.71 \%)$ & $12(17.65 \%)$ & $15(15.63 \%)$ \\
\hline $\begin{array}{l}\text { Overall response } \\
\text { rate (ORR) } \\
(\text { ORR ) }\end{array}$ & $12(42.85 \%)$ & $19(27.94 \%)$ & $31(32.30 \%)$ \\
\hline $\begin{array}{l}\text { Stable } \\
\text { disease(SD) }\end{array}$ & $12(42.85 \%)$ & $17(25.00 \%)$ & $29(30.20 \%)$ \\
\hline $\begin{array}{l}\text { overall clinical } \\
\text { response rate }\end{array}$ & $24(85.71 \%)$ & $36(52.94 \%)$ & $60(62.50 \%)$ \\
\hline $\begin{array}{l}\text { Progressive } \\
\text { disease(PD) }\end{array}$ & $4(14.28 \%)$ & $32(47.06 \%)$ & $36(37.50 \%)$ \\
\hline Total & $28(100 \%)$ & $68(100 \%)$ & $96(100 \%)$ \\
\hline
\end{tabular}

The main toxicities of chemotherapy were bone marrow suppression, gastrointestinal reactions and hepatotoxicity, all of which were mild (G1 or G2). Neutropenia and anemia were common in bone marrow depression, and all toxicities improved after supportive treatment. Twenty-two chemotherapy cycles $(6.47 \%)$ resulted in neutropenia of G3 or above, but no fever associated with neutropenia occurred. Thrombocytopenia of grade III or above occurred in 4 chemotherapy cycles $(1.18 \%)$, and purpura and gastrointestinal and intracranial hemorrhage related to thrombocytopenia did not occur. Nausea and vomiting were common among gastrointestinal tract reactions (23.06\%), and hepatotoxicity of G1 occurred in $19.41 \%$, and $\mathrm{G} 2$ occurred in $2.94 \%$. Two patients $(2.08 \%)$ received blood transfusions due to clinical toxicity, 5 patients $(5.21 \%)$ underwent chemotherapeutic dose reductions and had a prolonged chemotherapy cycle, one of which for liver damage, and the other four for bone marrow suppression. (Table 4)

Table 4 Percentage of toxicity in patients

\section{Discussion}

Although many remarkable achievements have been made in the treatment of ovarian cancer in recent years, second-line and later treatment regimens of platinum-resistant ovarian cancer are still unsatisfactory. In the relevant research on platinum-sensitive recurrent ovarian cancer, chemotherapy plans containing platinum were found to have an ideal curative effect; however, in patients with platinumresistant recurrent or acquired platinum-resistant disease during first-line chemotherapy, the efficacy of various chemotherapy drugs is not ideal. The overall response rates were as follows: weekly paclitaxel therapy was $20.9 \%^{[12]}$, docetaxel was $22.4 \%^{[13]}$, gemcitabine chemotherapy was $29 \%$, and bevacizumab 


\begin{tabular}{|c|c|c|c|c|c|}
\hline Toxicity & Grade I & Grade II & Grade III & Grade IV & \multirow{2}{*}{$\begin{array}{l}\text { was } 21 \%[5] \text {. Therefore, } \\
\text { prolonging the recurrence }\end{array}$} \\
\hline Anemia & $49 \square 14.41 \% \square$ & 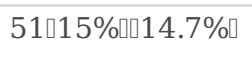 & $9 \square 2.65 \% \square 2.62 .65 \% \square$ & $1 \square 0.29 \% \square$ & \\
\hline Leukopenia & $27 \square 7.94 \% \square$ & 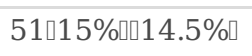 & $14 \llbracket 4.12 \% \square$ & $1 \square 0.29 \% \square$ & \\
\hline Neutropenia & $19 \square 5.59 \% \square$ & 46ロ13.53\%ם & $19 \square 5.59 \% \square$ & $3 \square 0.88 \% \square$ & improving the quality of life \\
\hline Thrombocytopenia & $13 \square 3.82 \% \square$ & $7 \square 2.06 \% \square$ & $4 \square 1.18 \% \square$ & - & of patients with ovarian \\
\hline Nausea / Vomiting & 63ロ18.53\%ם & $12 \square 3.53 \% \square$ & - & - & $\begin{array}{l}\text { cancer are focuses in the } \\
\text { current exploration of }\end{array}$ \\
\hline Diarrhoea/Constipation & $5 \square 1.47 \% \square$ & $4 \llbracket 1.18 \% \square$ & - & - & $\begin{array}{l}\text { ovarian cancer treatment. } \\
\text { Drug resistance and }\end{array}$ \\
\hline Hepatotoxicit-y & 66ロ19.41\%ם & $10 \square 2.94 \% \square$ & - & - & ovarian cancer are urgent \\
\hline Cardiac toxicity & $2 \square 0.59 \% \square$ & - & - & - & $\begin{array}{l}\text { problems that need to be } \\
\text { solved. }\end{array}$ \\
\hline Nephrotoxici-ty & $1 \square 0.29 \% \square$ & - & - & - & Pemetrexed disodium is a \\
\hline Mouth ulcer & $3 \sqsubset 0.88 \% \square$ & - & - & - & drug against folic acid that \\
\hline Neurotoxicity & $2 \llbracket 0.59 \% \square$ & - & - & - & has been approved by the \\
\hline Fatigue & $4 \llbracket 1.18 \% \square$ & - & - & - & FDA for the treatment of \\
\hline Skin rash & $1 \square 0.29 \% \square$ & - & - & - & $\begin{array}{l}\text { pleural mesothelioma and } \\
\text { nonsquamous non-small }\end{array}$ \\
\hline
\end{tabular}

cell lung cancer ${ }^{[8]}$. This drug was also studied in the treatment of ovarian cancer. It is gratifying that pemetrexed is also effective in the treatment of platinum-sensitive and platinum-resistant ovarian cancer, and the toxicity is mild ${ }^{[10,11,14,15]}$. The NCCN guidelines in 2019 recommended this drug for platinumsensitive and platinum-resistant recurrent ovarian cancer.

The present study confirmed the feasibility, efficacy and safety of pemetrexed in women with epithelial ovarian cancer, fallopian tube cancer, and primary peritoneal cancer. Among the 96 patients, 340 cycles of chemotherapy were completed (the median chemotherapy cycle number was 3 cycles), the ORR was $32.29 \%$ (31 patients), the overall clinical response rate was $62.5 \%$, and $37.5 \%$ (36 patients) patients developed disease progression. There were 28 platinum-sensitive patients and 68 platinum-resistant patients, and the ORRs were $42.86 \%$ (12 patients) and 27.94\% (19 patients), respectively; the difference was not statistically significant $(p=0.16)$. In previous studies, Matulonis et al. conducted a phase II clinical study of pemetrexed disodium $\left(500 \mathrm{mg} / \mathrm{m}^{2}\right.$ ) combined with carboplatin (AUC = 5) chemotherapy in platinum-sensitive recurrent ovarian cancer, with an ORR of $51.1 \%$ and no complete response ${ }^{[15]}$. In another phase II clinical trial ${ }^{[10]}$ of platinum-sensitive recurrent ovarian cancer, 66 patients with platinumsensitive recurrent ovarian cancer received pemetrexed disodium $\left(500 \mathrm{mg} / \mathrm{m}^{2}\right)$ combined with carboplatin (AUC $=6$ ) chemotherapy. The ORR of chemotherapy was $32.8 \%$. Vergote et al. ${ }^{[11]}$ conducted a phase II, randomized, double-blind trial in which 98 patients with platinum-resistant recurrent ovarian cancer or primary peritoneal cancer were treated with pemetrexed disodium (500 mg/m² or $\left.900 \mathrm{mg} / \mathrm{m}^{2}\right)$. 
The ORR of pemetrexed disodium $\left(500 \mathrm{mg} / \mathrm{m}^{2}\right)$ was $9.3 \%$, and the ORR of pemetrexed disodium $\left(900 \mathrm{mg} / \mathrm{m}^{2}\right)$ was $10.4 \%$. Another phase II clinical trial of pemetrexed for the treatment of recurrent or persistent platinum-resistant ovarian cancer or primary peritoneal cancer included 259 cycles of pemetrexed disodium $\left(900 \mathrm{mg} / \mathrm{m}^{2}\right)$ single-drug chemotherapy in 51 patients. The ORR was $21 \%{ }^{[14]}$. Based on these clinical experiences, pemetrexed combined with platinum is effective in the treatment of platinum-sensitive recurrent ovarian cancer, while pemetrexed alone is effective in the treatment of platinum-resistant recurrent ovarian cancer.

Therefore, the application value of pemetrexed in the treatment of epithelial ovarian cancer was confirmed. The median progression-free survival (PFS) of platinum-sensitive patients was 3.5 months (95\% Cl, 1.75-5.25), while platinum-resistant patients had a PFS of 2.97 months ( $95 \% \mathrm{Cl}, 2.47-3.47)$, respectively; there was no significant difference between the two groups $(p=0.06)$. However, the median overall survival (OS) of the two groups was 36 months and 18 months, respectively, and the difference was statistically significant $(P=0.01)$. For the antitumor effect, pemetrexed disodium has a similar effect in platinum-sensitive and platinum-resistant ovarian cancer, but platinum-sensitive patients seem to have a better long-term prognosis, which may be due to the increased efficacy of platinum in the treatment of platinum-sensitive recurrent ovarian cancer.

The toxic side effects of chemotherapy in 96 patients were mainly myelosuppression, gastrointestinal reactions and hepatotoxicity, all of which were mild reactions. After the appropriate supportive treatment, the side effects improved. The incidence of neutropenia of grade III and above was $6.47 \%$, and the incidence of thrombocytopenia of grade III and above was $1.18 \%$. There were no adverse reactions, such as purpura and gastrointestinal and intracranial hemorrhage, related to thrombocytopenia. Two patients (2.08\%) received blood transfusions, 5 patients $(5.21 \%)$ underwent chemotherapy dose reductions and had chemotherapy cycle prolongation. It can be seen that the side effects of pemetrexed in chemotherapy are tolerable, and the same results can be reflected in previous studies. In a phase I clinical trial conducted by Sehouli et al. ${ }^{[16]}$, only one case of grade IV hepatotoxicity was found in 20 patients, and no grade IV nonhematotoxicity was found. The most common toxicity was grade I in this trial, with one case of grade III nausea and one case of grade 3 anaphylaxis. In another phase II clinical trial conducted by Andrea R. et al. ${ }^{[17]}$, half of these patients had grade III-IV hematologic toxicity, of which neutropenia was the most common and severe. Common nonhematologic toxicities were fatigue and gastrointestinal reactions, which were mainly grade I-II. In conclusion, the side effects of pemetrexed chemotherapy are basically controllable and safe.

\section{Conclusion}

Compared with other chemotherapy drugs, pemetrexed disodium is effective for the treatment of epithelial ovarian cancer, epithelial fallopian tube cancer and primary peritoneal cancer. The toxicity of pemetrexed is basically controllable and is within the tolerable range. Therefore, pemetrexed disodium alone or combined with other chemotherapy drugs can be used as one of the options for the treatment of 
platinum-resistant and platinum-sensitive recurrent ovarian cancer. However, as a retrospective trial, the number of cases and the methods were still limited. Therefore, large-scale, multicenter, prospective randomized controlled trials are needed to evaluate the efficacy of pemetrexed in ovarian cancer.

\section{Abbreviations}

CA125

Carbohydrate antigen-125

$\mathrm{CR}$

Complete response

FDA

Food and Drug Administration

G-CSF

Granulocyte colony-stimulating factor

NCCN

National Comprehensive Cancer Network

NSCLC

Nonsquamous non-small cell lung cancer

ORR

Overall response rate

OS

Overall survival

PD

Progressive disease

PFS

Progression-free survival

PR

Partial response

SD

Stable disease

\section{Declarations}

Ethics approval and consent to participate: The present study was approved by the Ethics Committee of Shandong University Qilu Hospital. Written informed consent was obtained from all patients.

Consent for publication: Not applicable.

Competing interests: The authors declare that they have no competing interests. 
Availability of data and materials: The datasets used and analyzed during the current study are available from the corresponding author on reasonable request.

Funding: This study was funded by National Nature Science Foundation of China 81772778 to J.J囚and Shandong Province Key Research \& Development Program『2017GSF18175 to J.J).

Authors' contributions: Yanmei Wu collected the data, drafted the manuscript and statistical analysis; Jie Jiang contributed to the study design and revised the manuscript

Acknowledgements: Not applicable.

\section{References}

1. Torre LA, Trabert B, DeSantis CE, Miller KD, Samimi G, Runowicz CD, et al. Ovarian cancer statistics, 2018. CA Cancer J Clin 2018; 68(4):284-296.

2. Jelovac $D$, Armstrong DK. Recent progress in the diagnosis and treatment of ovarian cancer. $C A$ Cancer J Clin 2011; 61(3):183-203.

3. Gordon AN, Tonda M, Sun S, Rackoff W, Doxil Study I. Long-term survival advantage for women treated with pegylated liposomal doxorubicin compared with topotecan in a phase 3 randomized study of recurrent and refractory epithelial ovarian cancer. Gynecol Oncol 2004; 95(1):1-8.

4. Ferrandina G, Ludovisi M, Lorusso D, Pignata S, Breda E, Savarese A, et al. Phase III trial of gemcitabine compared with pegylated liposomal doxorubicin in progressive or recurrent ovarian cancer. J Clin Oncol 2008; 26(6):890-896.

5. Burger RA, Sill MW, Monk BJ, Greer BE, Sorosky JI. Phase II trial of bevacizumab in persistent or recurrent epithelial ovarian cancer or primary peritoneal cancer: a Gynecologic Oncology Group Study. J Clin Oncol 2007; 25(33):5165-5171.

6. Hanauske AR, Chen V, Paoletti P, Niyikiza C. Pemetrexed disodium: a novel antifolate clinically active against multiple solid tumors. Oncologist 2001; 6(4):363-373.

7. Chattopadhyay S, Moran RG, Goldman ID. Pemetrexed: biochemical and cellular pharmacology, mechanisms, and clinical applications. Mol Cancer Ther 2007; 6(2):404-417.

8. Gyawali B, Prasad V. Pemetrexed in Nonsquamous Non-Small-Cell Lung Cancer: The Billion Dollar Subgroup Analysis. JAMA Onco/2018; 4(1):17-18.

9. Roche M, Parisi L, Li L, Knehans A, Phaeton R, Kesterson JP. The role of pemetrexed in recurrent epithelial ovarian cancer: A scoping review. Oncol Rev 2018; 12(1):346.

10. Sehouli J, Alvarez AM, Manouchehrpour S, Ghatage P, Szczylik C, Zimmermann A, et al. A phase II trial of pemetrexed in combination with carboplatin in patients with recurrent ovarian or primary peritoneal cancer. Gynecol Oncol 2012; 124(2):205-209.

11. Vergote I, Calvert H, Kania M, Kaiser C, Zimmermann AH, Sehouli J. A randomised, double-blind, phase II study of two doses of pemetrexed in the treatment of platinum-resistant, epithelial ovarian or 
primary peritoneal cancer. Eur J Cancer 2009; 45(8):1415-1423.

12. Gynecologic Oncology G, Markman M, Blessing J, Rubin SC, Connor J, Hanjani P, et al. Phase II trial of weekly paclitaxel $(80 \mathrm{mg} / \mathrm{m} 2)$ in platinum and paclitaxel-resistant ovarian and primary peritoneal cancers: a Gynecologic Oncology Group study. Gynecol Oncol 2006; 101(3):436-440.

13. Rose PG, Blessing JA, Ball HG, Hoffman J, Warshal D, DeGeest K, et al. A phase II study of docetaxel in paclitaxel-resistant ovarian and peritoneal carcinoma: a Gynecologic Oncology Group study. Gynecol Oncol 2003; 88(2):130-135.

14. Miller DS, Blessing JA, Krasner CN, Mannel RS, Hanjani P, Pearl ML, et al. Phase Il evaluation of pemetrexed in the treatment of recurrent or persistent platinum-resistant ovarian or primary peritoneal carcinoma: a study of the Gynecologic Oncology Group. J Clin Oncol 2009; 27(16):26862691.

15. Matulonis UA, Horowitz NS, Campos SM, Lee H, Lee J, Krasner CN, et al. Phase Il study of carboplatin and pemetrexed for the treatment of platinum-sensitive recurrent ovarian cancer. $J$ Clin Oncol 2008; 26(35):5761-5766.

16. Sehouli J, Camara O, Mahner S, Bauknecht T, Lichtenegger W, Runnebaum I, et al. A phase-I trial of pemetrexed plus carboplatin in recurrent ovarian cancer. Cancer Chemother Pharmacol 2010; 66(5):861-868.

17. Hagemann AR, Novetsky AP, Zighelboim I, Gao F, Massad LS, Thaker PH, et al. Phase Il study of bevacizumab and pemetrexed for recurrent or persistent epithelial ovarian, fallopian tube or primary peritoneal cancer. Gynecol Oncol 2013; 131(3):535-540.

\section{Figures}




\section{PFS}

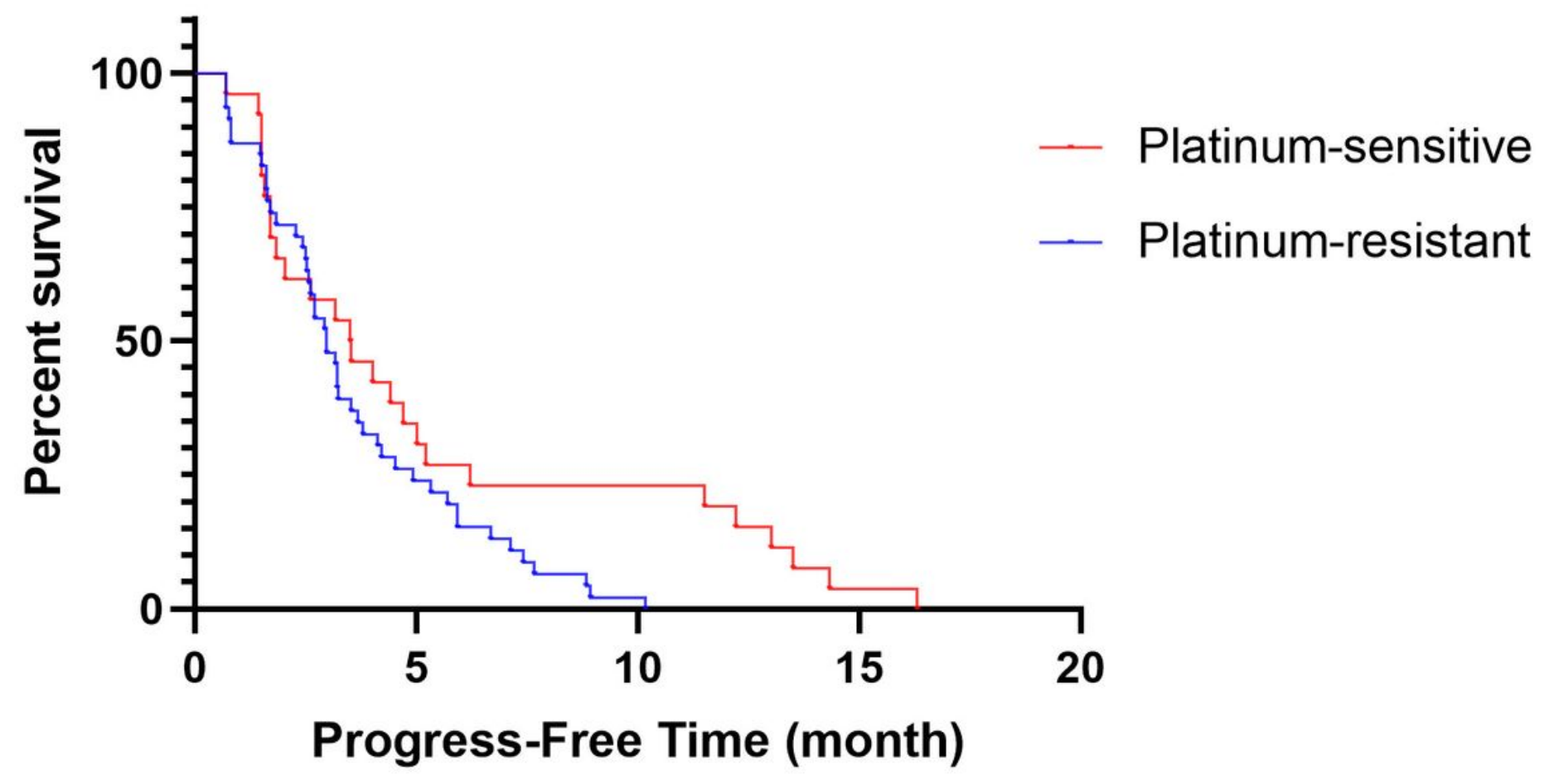

Figure 1

Kaplan-Meier curve of progress-free time (PFS)凹Made by GraphPad Prism8.0.1区 


\section{OS}

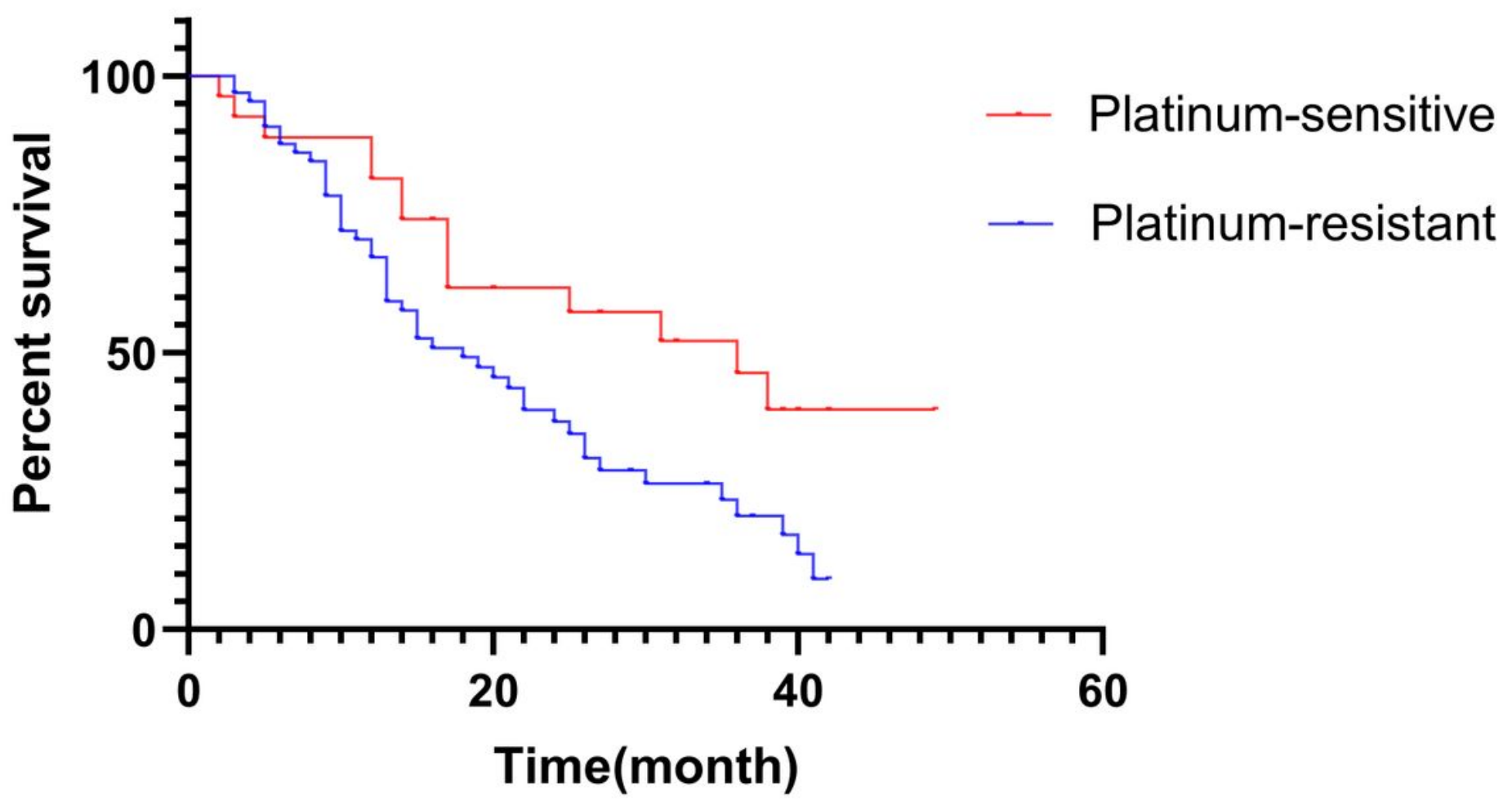

Figure 2

Kaplan-Meier curve of overall survival (OS)『Made by GraphPad Prism8.0.1】 